\title{
The paradox of contemporary Medicine
}

\author{
Florindo Pirone \\ Dirigente f.r. Ospedale Sandro Pertini, Roma, Italy
}

\begin{abstract}
In the medical field, between the end of the $19^{\text {th }}$ century and the half of last century, great results were obtained in the discovery of the causes (microbial agents) and cures (antibiotics) of infectious diseases, which in the previous centuries had determined catastrophic epidemics. The successes of this model of disease led to apply it in the cases of other pathologies including cardiovascular, respiratory and oncological ones. Despite the great effort during the following years, with all the innovations both in diagnostic field (sophisticated lab and instrumental tests) and in therapies (the development of numerous heart and circulatory drugs or against neoplasia), improvements have been proportionally less impressive. Compared to the first half of last century, 27 years of life have been gained, from an average life span of 55 years to 81 for men and 84 for women. The 17-year gain has been possible thanks to the decisive action on the infectious diseases, whereas the intervention on heart diseases led to a gain of 7 years of life, and that on the neoplastic ones resulted in a gain of $3 / 4$ years.

This discrepancy depends on several reasons, among which a fundamental one is the difference between the models of the infectious disease and other pathologies: the first ones are characterized by only one agent attacking the organism in a short time and can be eliminated only by one drug (the antibiotic), used for a short time as well; in the case of other diseases, the pathogens are multifactorial, the damaging actions take place over many years and possible therapies must be multiple and performed over a long period of time.

There has been a shift from a simple to a complex issue, to the extent that some believe that only new technologies of artificial intelligence (AI) will be able to offer effective remedies. If we add to all this the idea that for several reasons, both socio-cultural and inherent to this discipline, Medicine has been taking on more and more reductionism and detached stands, one might understand the current perceptive paradox We have never been better, we have never felt so bad. Thus, it has become necessary to meditate upon these topics in order to better understand the real problems and possible solutions to the benefit of that essential good for everyone, our health.
\end{abstract}

\section{We have never been better, we have never felt so bad}

Last century has brought about remarkable and consistent developments in medicine. In this respect, World War II represents a turning point: in the first

\author{
Correspondence: Florindo Pirone, Dirigente f.r. Ospedale San- \\ dro Pertini, Roma, Italy. \\ E-mail: florindo.pirone@virgilio.it
}

Key words: Sociology of medicine; disease models; scientific reductionism and holism.

Conflict of interests: the authors declare no potential conflict of interests.

Received for publication: 8 September 2019

Accepted for publication: 6 November 2019.

This work is licensed under a Creative Commons Attribution NonCommercial 4.0 License (CC BY-NC 4.0).

${ }^{\circ}$ Copyright: the Author(s), 2020

Licensee PAGEPress, Italy

Italian Journal of Medicine 2020; 14:9-13

doi:10.4081/itjm.2020.1211 half of the century there was the so-called therapeutic nihilism during which doctors witnessed hopelessly the insurgence of many diseases; the possible actions could be summed up in three Ps: placebo, palliative, purgative. ${ }^{1}$ In the second half of the century instead, there was a ground-breaking change: truly effective cures started to appear with the introduction of antibiotics. Since then, progress in knowledge has been unceasing both in the diagnostic and therapeutic fields. Life span expectation stands as evidence of this change. Indeed, life span has increased from 55 years in the first half of the twentieth century to the current 82 years, with an average gain of 27 years of life. Despite such remarkable successes, the trust of citizens in medicine is not as strong as one may expect. For example, in the United Kingdom only $53 \%$ of the population declares to be satisfied with the health system, while $29 \%$ of it declares to be unsatisfied, a percentage that keeps increasing in the latest years. ${ }^{2}$

Moreover, there are three more indexes of this contradiction: the percentage of doctors that are unsatisfied with their profession has been increasing steadily: from $41 \%$ in 1966 to $58 \%$ in 1986 . In the last thirty years the percentage of citizens concerned about their health has increased from $10 \%$ to $50 \%$ (the so-called healthy concerned). In the United States, the requests 
for alternative medicine practices (425 mil) are greater than those for scientific medicine (388 mil). ${ }^{3}$ European surveys confirm this trend with about 100 million European citizens and $23 \%$ of the Italian population requesting alternative medicine practices. ${ }^{4}$

Therefore, we are facing a seeming paradox: distrust in scientific medicine of a great portion of citizens, despite so many unquestionable developments. The statement we have never been better, we have never felt so bad well describes this situation. There are several and deep reasons supporting this contradiction, which can be divided in three different categories: historic, methodological, and socio-economic and cultural.

For centuries, mankind has been plunged with epidemics such as the plague, smallpox, cholera, and tuberculosis causing the death of thousands of people in a very short time, generating fear and anguish. Only in the second half of the $19^{\text {th }}$ century medicine was able to devise effective methods to fight them. Thanks to researchers like Pasteur and Koch the microbial cause of infectious diseases was discovered, which quickly gave the way to prevention through personal and public hygiene and vaccination. Almost sixty years had to pass after Pasteur's vaccine to discover the first effective molecule against bacteria thanks to Alexander Fleming. In 1928 Fleming by chance comprehended the anti-microbial power of mold, the Penicillium chrysogenum. Thus, penicillin was born, which could be clinically used after extensive research only in 1942 .

After the production of the first antibiotic, pharmaceutical research has never halted, allowing mankind to take a leap in life expectancy, discussed above. The remarkable results obtained in the fight against infectious diseases led to believe that the model of this type of diseases could be applied to all other pathologies.

Thus, in the collective imagination, antibiotic became the magic bullet able to kill assassin microbes, and the hope was to discover more magic bullets to target directly and quickly silent killers, such as high blood pressure or cancer agents lurking against human organisms. ${ }^{5}$

In the second half of the twentieth century, this model turned out to be not applicable to the new epidemics of chronic diseases caused not only by one agent but by multiple internal and external factors in the organism. Indeed, out of the 27 years gained in the average lifespan, 17 years are attributable to the effective intervention on infectious diseases, whereas the action on heart diseases led to a gain of 7 years of life, and on neoplastic diseases only $3 / 4$ years. ${ }^{6}$

After achieving control on infectious diseases, new pathologies emerged including degenerative and neoplastic ones, which did not fit the predictive model of one specific external agent. Balance could be broken by dynamically interacting multiple factors, that could be originated by the same sick organism, acting silently for years.

The model of infectious diseases, in which the cause of symptoms is one, presents a sharp course of action and can be cured by a specific drug as opposed to the course of the new chronic epidemics, which are multifactorial, possibly silent for many years, curable only by multiple therapies and for a long period of time.

There has been a shift from a simple to a complex situation, difficult to manage.

The effects of this different paradigm and the concurrent greater challenges in the diagnosis and treatment, point out the first reason of contemporary discontent: the great results obtained by Medicine with infectious diseases have generated a great expectation with all other pathologies. Mistrust and disappointment quickly followed when progress was not as fast and thorough as desired in the fight of other diseases. The great developments of Medicine have made people forget their own limits and nurture unrealistic expectations.

The second reason of the mistrust in Medicine can be defined as methodological and originates in the need to face the complexity of other diseases, other than the infectious ones, following new routes.

The formidable drive towards the search for the causes of many diseases, including cardiac, oncological, autoimmune, dysmetabolic ones, has led to a knowledge by reduction, a characteristic trait of modern Medicine, modelled on modern Science. ${ }^{7}$

The reductionist method is based on the breaking down of problems into simpler problematic elements, more and more idealized, and as such easier to be analyzed, considering that every reality - though appearing complex - is the sum of its components. A system consisting in many interacting parts should be subdivided into narrower departments so to allow the study of its most elementary properties. ${ }^{8}$

This method has fundamentally contributed to the great knowledge expansion of Medicine and has spurred the birth of specializations, as it has happened to all other scientific disciplines. These specializations have narrowed the field of study, dedicating to the analysis of individual apparatus or even single organs, down to the molecular level, and devising more and more sophisticated research techniques.

Avoiding the question whether it is possible to transform reductionism from a method of investigation into a theoretical principle - a shift contested by those who believe that in a complex system new properties arise, different from its basic components (the whole is greater than the sum of each part) - there are some important consequences in the medical field that derive from this transformation and as such deserve to be discussed. 
Specializations have multiplied and currently there are 48 different specializations in University Medicine departments, which have further diversified in subspecializations in the medical practice.

Also, the lab and equipment investigations have become more and more sophisticated and specific; Ultrasound is now followed by computed tomographic scan, magnetic resonance imaging, positron-emission tomographic (PET) scan, genomic research and information technology (IT).

Many authors have highlighted that in this powerful study method there are inherent limits when it is applied to the medical field, a discipline that has humans as point of reference, in which the physic-biological dimensions are followed by psychological, ethical and social realms.

According to G. Israel, the knowledge by reduction has led to the disintegration of the body into many pieces deriving from an objectivist approach of medicine that substitutes the idea of the cure with the idea of reparation, neglecting the sick person and making irrelevant the role of the clinic. ${ }^{9}$

Physician Guido Melli, speaking about specializations, affirmed that the objective of the specialist is to know more and more about something that is more and more limited, to reach a point of knowing everything about nothing. ${ }^{10}$

The need to find a balance between positive and unwanted aspects of this method was described by physician G. Federspil in an article with a meaningful title: Challenge to our medical culture: the physician today between people and molecules, in which the author recognizes the undeniable merits of the methodological reductionism but also underlines the need of doctors to have a global, holistic vision. ${ }^{11}$

A provocative title of a series of articles by the Journal of American Medical Association wants to stigmatize the dangers of wide-spread excessively reductionist approach: Less is more, which means less health care can lead to more health. ${ }^{12}$

The second reason for the mistrust is thus connected to the reductionist approach that has surely strengthened the ability to explore changes in greater details, but has also often led to the risk of losing the global, holistic view: the patient is juggled from one doctor to the other, without an apparent awareness of the priorities to follow and without a point of reference. The attention seems focused more on the biological dysfunction rather than the experienced suffering.

To sum up, the excessive specialization has added another element to the crisis of trust in Medicine, as it has decreased the power of the appropriate application of technology, and of the clinical relation between physician and patient, inducing a vision of the patient as a machine with a fault to fix.
In October 1986, in Ottawa, Canada, the First International Conference on Health Promotion took place, and it produced what is now known as the Ottawa Charter for Health Promotion, which is defined as a state of complete physical, social and psychological well-being, and not only the absence of disease or illness. At that time many people considered this definition as delusive for its ambition to a complete well-being that is unachievable. Yet indeed, this definition represented an expansion of the concept of disease from a mere alteration of a biological structure or function to those personal phenomenological (mental well-being) and collective (social well-being) aspects. ${ }^{13}$

The concept of disease, although apparently clear to everyone, is a complex and difficult notion to define. A concept, moreover, that changes over the history of mankind and whose meanings strongly impact the physician-patient relationship. Over the years, the definition of disease has transformed from an anatomical-functional alteration of an organ or apparatus, that is followed by patient's distress, to a deviation from a normal statistic interval, even without symptoms, to a genetic-molecular condition that determines a potential risk. In addition, all these notions were impacted by the different socio-economic scenario in which they took place. ${ }^{14}$

We have then moved from the individual medicine based on the doctor to be called in by the patient (following the old saying medicus non accedat nisi vocatur) to a pro-active approach with doctors advising the general public to do screenings as if searching for patients to cure, regardless of the symptoms or distress of the patient, but on the basis of the presence of some lab or instrumental parameters; until the latest additional expansion of the notion of illness - still ongoing - thanks to the opportunity to go deeper and deeper in the investigation of the human body, to the point of using probes able to draw maps of predictive genes of probable diseases, many years before they would appear and with all the relative doubts on how to manage such conditions.

The changes in the idea of disease have been accompanied by a rising economic crisis and a struggle to manage specific diseases ever so spread and costly in their diagnosis and treatment. The vision of what a disease really is, or a simple non-treatable variation, had to deal with these economic aspects (for example, a woman's infertility due to causes that could be solved by costly treatments is to be considered a disease or a personal desire?).

The same question could be asked with regard to specific lifestyles such as alcohol consumption or smoking cigarettes, as their biological consequences (lung and liver-related diseases) were ascribed to individuals' behaviors rather than to specific health treatments provided to and paid by the public. 
The weight of economic elements in Healthcare is due to the fact that research and production of new pharmaceuticals have become more difficult and costly. Only in 2017, the 10 biggest Pharma in the world turned over 437,26 billion dollars ( $40 \%$ of the global market), much more than the GDP of the majority of world's nations. The global pharmaceutical market amounts to 1000 billion dollars and it is forecasted to reach 1400 billion dollars within $2020 .^{15}$

Pharmaceutical industries invest in Research \& Development and in marketing, respectively, $12 \%$ and $30 \%$ of their expenses. ${ }^{16}$

In the latter part of the last century and in the first half of the new one, two determining factors of the relations between doctors and their patients have arisen: IT and the standardization of such relations by designed protocols. At the beginning, the relation between patient and doctor was direct, with the first asking the second for help, and the second - by science and moral integrity - coming up with solutions deemed most appropriate for that instance. Currently, the relation has been mediated: no longer is the patient spontaneously activating the request for the doctor's intervention, and the latter now has to go through several regulations limits (definition of health issues requiring assistance, the duration of the recommended assistance, the levels of public expenditure, the established therapeutic protocols, etc.).

As a consequence, the relationship based on trust of a single doctor has been replaced with a fragmentary rapport: with a medical team, with specialists, with an administrative-bureaucratic system. Often literature is able to describe the common feeling of an era in a more powerful way than what can be done by scientific articles or studies. ${ }^{17}$ Regarding some of the shadows of contemporary medicine, here what two authors affirm. Jules Romains in his Dr Knock or the Triumph of Medicine in 1923, represented the risk of the society to be transformed in a community of sick people, as he writes: To be healthy in truth is the ignorance of being sick. ${ }^{18}$

Almost a century later, Daniel Pennac in his Diary of a Body in 2013, has written today's doctor only cares about the cellular puzzle, the ultrasound scanned body, the PET scanned body, analyzed body, biological, genetic, molecular body, the factory of antibodies. ${ }^{19}$

In this widespread feeling there is the third reason of dissatisfaction. The exponential and pervasive development of medicine risks sometimes the medicalization of human life, making it distressing. ${ }^{20,21}$

This is exactly the opposite to the concept of vis medicatrix naturae, which was still present in the idea of disease in the first half of the last century, conceiving man in harmony and balance with the universe. ${ }^{22}$ This holistic vision was embraced by those practices known as alternative and complementary medicine, deemed irrational by the traditional medicine, which however take into great consideration essential and deep needs of humankind. ${ }^{23}$

Considering these difficult and contrasting conditions faced by Medicine, some authors affirm that only IT through AI could overcome the ambiguities and uncertainties so negatively impacting contemporary Medicine. ${ }^{24}$

The implication of AI's applications to medicine are particularly complex and deeply evolving, however, some brief considerations can be shared with regard to the above-mentioned topics.

A medical action is made of three basic moments: anamnesis, diagnosis, therapy. In all steps, physicians must rely on probabilities: the lamented symptoms by the patient and investigated by the doctor are essentially subjective and it is not possible to sum them up in a comprehensive questionnaire; the presented pathological syndromes are generally compatible with more diseases with different degrees of probability and therapies' results are only partially foreseeable (a percentage of success will be achieved but it is unknown on which patient they will be successful).

Medicine is the science of uncertainty and the art of probability as affirmed by the founder of American Medicine W. Osler in order to underline these characteristics of medicine, which are structural and inherent in the method itself, and as such they are unavoidable. ${ }^{25}$

$\mathrm{AI}$, as currently known, can have a positive role in gathering great amount of data and analyzing them with great speed, with error decrease (there are more than 10,000 diseases). However, it cannot eliminate the intrinsic uncertainties of the three basic medical moments.

Thus, it is necessary to avoid creating unreal illusions that would further increase the list of widespread unjustified expectations. Beyond the future capabilities of AI in the medical field, it is important not to neglect the dangers and damages that currently Information Technology causes in medicine, leading to an even further dehumanization of clinical practice.

As a matter of fact, the majority of physicians spend $40-50 \%$ of their working time looking at a computer screen to fill in a form or analyze medical records, to book instrumental tests or download lab analyses or online pharmaceutical prescriptions. The traditional bedside visit of the doctor to his patient now has been substituted by a briefing in a room away from the patients, analyzing images, data, information on screen. ${ }^{26}$

On the basis of what has been discussed, there is a need of what has been defined as new pact between the doctor and the patient; both patients and doctors have to be aware of the fact that:

- Death, disease and pain belong to life; 
- Medicine has limited powers, especially when dealing with social problems, and itself can be a risk;

- Doctors do not know everything: they have to make a decision in difficult situations that require reciprocal psychological support;

- Doctors and patients are ally;

- Patients can delegate their problems to doctors;

- Doctors should be open about their limits and try to hold a holistic view;

- Everyone should avoid making promises or extravagant requests that are far from reality. ${ }^{27}$

In his wonderful film Wild Strawberries by Swedish director Bergman, there is an old doctor who, at the end of his life, dreams of facing one last test evaluating his entire professional career. The Examining Board asks him several technical questions which he promptly answers. However, when they ask him What is the first duty of a physician, he is puzzled, remains quiet and then stutters some nonsense. This question, as deep questions do, does not have one single answer. However, one relevant answer can be found in a work of Scandellari, already mentioned, that superbly sums up the essence of what I have tried to express: The physician must realize that his patient is reaching out to him not only to be informed of the label of his disease (diagnosis), rather, to be understood before being cured; (...) to discuss with him his present quality of life and how it is possible to improve it or to make it bearable.

\section{References}

1. Mukherjee $\mathrm{S}$. Le regole della cura. La medicina è un racconto. Milano: Rizzoli; 2016.

2. Robertson R, Appleby J, Evans H, Hemmings N. Public satisfaction with the NHS and social care in 2018: Results from the British Social Attitudes survey; March 2019. Available from: https://www.kingsfund.org.uk/sites/default/files/2019-03/Public_satisfaction_with_NHS_social_care_in_2018.pdf

3. Le Fanu J. The rise and fall of modern medicine. London: Abacus; 2011.

4. Rapporto Annuale Censis 2008. Available from: http: //www.ordinemedicifc.it/wp-content/uploads/2016/ 10/LE-MEDICINE-NON-CONVENZIONALI-INITALIA LA-SITUAZIONE-ATTUALE.pdf

5. Heynick F. The original 'magic bullet' is 100 years old extra. Br J Psychiatr 2009;195:456.

6. D'Amore F. L'importanza della diagnosi etiologica: la lezione delle malattie infettive. Congresso FADOI Lazio, Novembre 2018, Roma, Italy.

7. Cavicchi I. Ripensare la medicina. Restauri, reinterpre- tazioni, aggiornamenti. Torino: Bollati Boringhieri; 2004.

8. Scandellari C. Medicina dei liberi e degli schiavi. Lezione tenuta ai Medici della Regione Friuli-Venezia Giulia al Castello di Spessa (UD), 10 dicembre 2010.

9. Israel G. Per una medicina umanistica. Apologia di una medicina che curi I malati come persone. Torino: Edizioni Lindau; 2010.

10. Rugarli C. Medici a metà. Milano: Raffaello Cortina Editore; 2017.

11. Atti del Convegno "Medicina e sanità a confronto con la multiculturalità"- Fnomceo, 23-24 novembre 2007, Padova, Italy.

12. The JAMA Network. Specialties \& topics, less is more. Available from: https://jamanetwork.com/journals/jamainternalmedicine/pages/about

13. World Health Organization. The Ottawa Charter for health promotion; 21 November 1986. Available from: https://www.who.int/healthpromotion/conferences/previous/ottawa/en/

14. World Health Organization. The Ottawa Charter for Health Promotion; 21 November 1986. Available from: https://www.who.int/healthpromotion/conferences/previous/ottawa/en/

15. Pirone F. The concept of illness in the physician-patient relationship. Ital J Med 2018;12:227-9.

16. Federazione delle Associazioni Italiane degli Informatori Scientifici del Farmaco (FEDAIISF). Multinazionali farmaceutiche, le Top 10 nel 2018; 27 settembre 2018. Available from: https://www.fedaiisf.it/top-10-dellemultinazionali-farmaceutiche-nel-2018/

17. Vineis P, Dirindin N. In buona salute. Torino: Einaudi; 2004.

18. Di Napoli M. La malattia e la morte raccontate dai grandi della letteratura. Roma: Armando Editore; 2019.

19. Romains J. Knock o Il trionfo della medicina. Macerata: Liberiliberi; 2008.

20. Pennac D. Storia di un corpo. Milano: Feltrinelli; 2014.

21. Smith R. Limits to medicine. Medical nemesis: expropriation of health. J Epidemiol Commun Health 2003;57:928.

22. Cerecedo Perez MJ. Medicalization of life at GP level: were we headed to? Aten Primaria 2013;45:536-40.

23. Hirosh H. On vis medicatrix naturae and Hippocratic idea of physis. Memoirs of School of Health Sciences, Faculty of Medicine (Kanazawa University); 1998, 22:45-54

24. Zarifian É. Éloge du placebo. Actual Méd Int Psychiatr 1987;48:1187-8.

25. Zaccagnini D. Moving boxes. Roma: L'asino d'oro; 2015.

26. Bean RB, Bean WB. Sir William Osler: aphorisms from his bedside teachings and writings. Yale J Biol Med 1950;23:162-3.

27. D'Amore F, Pirone F. Doctor 2.0 and i-Patient: information technology in medicine and its influence on the physician-patient relation. Ital J Med 2018;12:1-4. 